\title{
Cyclodextrinic carcerands. I. Would they form inclusion complexes? Computational study on structure and energetics
}

\author{
Kepa K. Burusco, ${ }^{\text {a Petko M. Ivanov, }}$, a,b and Carlos Jaime*,a \\ ${ }^{a}$ Department de Química, Facultat de Ciències, Universitat Autònoma de Barcelona, \\ 08193 Bellaterra, Spain \\ ${ }^{b}$ Institute of Organic Chemistry with Center of Phytochemistry, Bulgarian Academy of Sciences, \\ 1113 Sofia, Bulgaria \\ E-mail: carlos.jaime@uab.es
}

Dedicated to Professor José Elguero on his $70^{\text {th }}$ birthday

(received 24 Dec 04; accepted 05 Apr 05; published on the web 14 Apr 05)

\begin{abstract}
A structural and energetic study on three types of cyclodextrinic carcerands formed by linking two units of $\alpha$-, $\beta$-, or $\gamma$-cyclodextrin through methylene chains of several lengths was performed by molecular mechanics, and molecular dynamics simulations. The smaller carcerands are rigid and spherical, while the larger carcerands are more flexible, their cavities are more hidden, and they are spheroidal. The small carcerands having one bridge per glucose present "laevo", symmetrical, and "dextro" arrangements due to the formation of hydrogen bonds between the two CD units, while those with two bridges per glucose present only two conformations (symmetric and asymmetric). All the geometrical characteristics become more diffuse when the size of the cavity increases.
\end{abstract}

Keywords: Cyclodextrins, carcerands, molecular dynamics

\section{Introduction}

Intensive studies have been carried out by our group on cyclodextrins (CDs) ${ }^{1,2,3}$ in view of the increasing interest in these structures in various areas of chemistry which was provoked by their potential to encapsulate small molecules. The applications of these inclusion complexes cover, among others: molecular recognition, stabilization of substances sensible to air and light, modification of the activity of molecules included in the macro-ring cavity, immobilization of volatile substances, modification of the physicochemical properties of the guest molecules, and transport of non-polar organic substances in polar media (CDs have predominantly hydrophobic cavities and hydrophilic external walls). Following the same line of research, we focused 
recently on inclusion complexes with the participation of two cyclodextrins, dimers of bridged cyclodextrins, ${ }^{4}$ as well as large-ring cyclodextrins. ${ }^{5,6}$

The increased interest towards systems based on derivatives of $\mathrm{CD}$ dimers as selective complexation agents ${ }^{7,8}$ was further increased by the successful synthesis of molecules of this type, ${ }^{9,10}$ a fact of outstanding importance by itself. References can also be found in the synthetic accessibility of such products that have diverse characteristics: ${ }^{11,12}$ linear chains of different lengths, rigidity, number and type of heteroatoms. ${ }^{13}$ The bridged dimer with two aliphatic chains (Figure 1$)^{14}$ is a case of particular significance because it represents an important intermediate step towards the derivation of macromolecules interbridged by several chains.

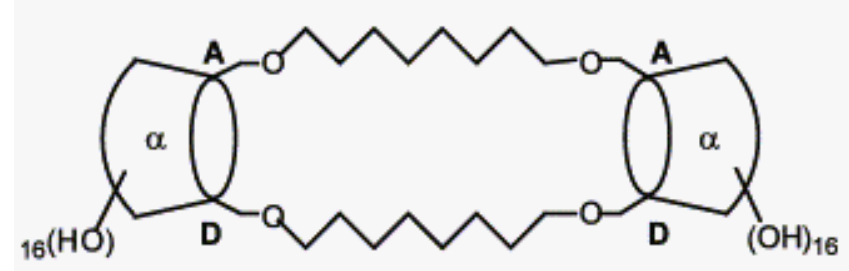

Figure 1. A CD dimer with two bridges interconnecting the two $\alpha$-CDs through the primary hydroxyls (the narrower rims).

The macromolecules studied in this work are formed by two CD units interconnected by aliphatic chains through the secondary hydroxyls (Figure 2). The cavity is enclosed by the CDs and the bridging chains. The size and the shapes of the cavity vary as a function of the type of the $\mathrm{CD}$, and the length and number of chains. These molecules attracted our attention because of their potential to form inclusion complexes and to recognize other molecules in the same manner as the CDs. Moreover, the presence of two CDs in one and the same macromolecule may elevate these properties. In this sense, we can consider these molecules as carcerands (a natural extension in the evolution of macromolecules that contain CD dimmers). The carcerands are closed molecular containers that usually do not have entrances large enough to allow guest molecules to enter and exit freely. ${ }^{15}$

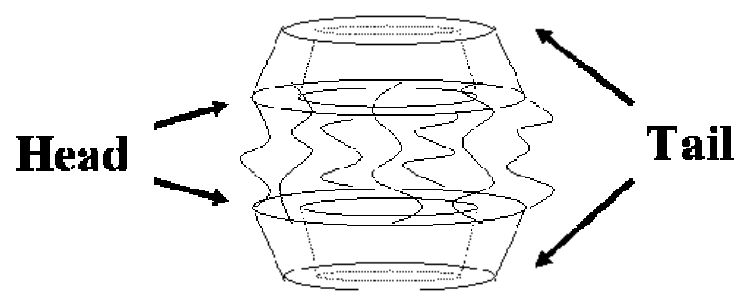

Figure 2. Schematic representation of a cyclodextrinic carcerand. 
The various types of CD-carcerands we have studied were generated by modifying the following parameters: (i) the CDs; (ii) the chain length; (iii) the number of chains (i.e., the number of chains per glucose); (iv) the bridging atoms at the two CDs. The three native CDs ( $\alpha$-, $\beta$-, and $\gamma-\mathrm{CD}$ ) interconnected through their wider rim were considered in this study. Chains containing 1, 3, 6 and 9 methylene groups were used. Up to two hydroxyl groups from each glucose residue can participate in bridges, and thus two possibilities exist for each glucose unit - to have one or two bridges. Assuming the orientations of the two CDs as to be head-head (facing the two wider rims) and marking the atoms of connection $\mathrm{C}(2)$ and $\mathrm{C}(3)$ as 2 and 3 , the following unique possibilities for designating the carcerands resulted: [2.2], [2.3], [3.3] for the one-link cases, and [2.2], [2.3] for the carcerands with two bridges per glucose residue (Figure $3)$.

a)

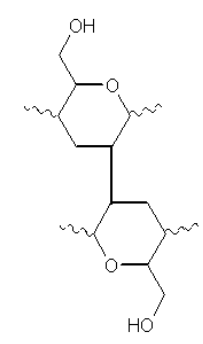

[2.2]

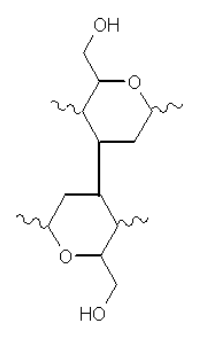

$[3.3]$

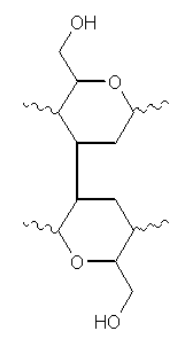

[2.3]

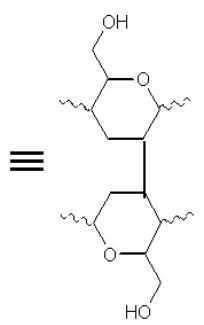

[3.2]

b)

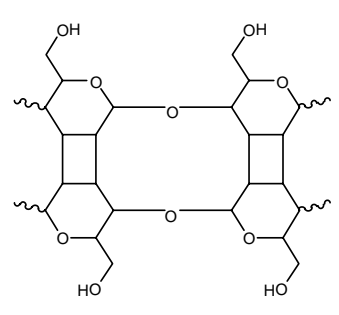

[2.3]

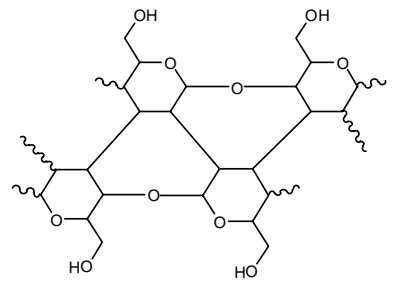

[2.2]

Figure 3. (a) Carcerands with one bridge per glucose: seemingly four possibilities exist, but [2.3] and [3.2] are equivalent by $180^{\circ}$ rotation; (b) Carcerands with two bridges per glucose: [2.3;3.2] and [2.2;3.3] will be designated as [2.3] and [2.2] for brevity.

All the studied carcerands were designated with names that contain the necessary information to identify their structures. The derivation of the names followed the same rules we used to generate the structures: (i) $a, b$ and $g$ designate, accordingly, $\alpha-, \beta-$, and $\gamma-C D$; (ii) next follow two numbers corresponding to the number of chains connecting the two CDs- $-06,12,07$, 14, 08, or 16; (iii) the third group have two digits that refer to the number of methylene groups in the chains - 01, 03, 06 or 09; and (iv) the last group designates the 'isomerism of connectivity' $-22,23$, or 33 . As an example, the carcerand named as a120923 is formed by two $\alpha-C D s$, linked by 12 chains of 9 methylene units each and bonded between the O-2 of one CD 
and the O-3 of the other. It has also been assumed that rotational symmetry exists with respect to the main axis passing through the center of the $\mathrm{CD}$, i.e., once the type of connectivity for a pair of glucoses is proposed, all other pairs of glucose residues follow the same rules of connectivity along the itinerary of the macro-rings. With these restrictions, the total number of structures studied in the family of carcerands was 60 (Table 1).

Table 1. The total set of 60 carcerands studied. There are two columns per system depending of the number of chains per glucose: one (left column) or two (right column). Carcerands marked in bold produced poor clusterings

\begin{tabular}{cc|cc|cc}
\hline \multicolumn{2}{c|}{ Alfa } & \multicolumn{2}{c|}{ Beta } & \multicolumn{2}{c}{ Gamma } \\
\hline $\mathrm{a} 060122$ & $\mathrm{a} 120122$ & $\mathrm{~b} 070122$ & $\mathrm{~b} 140122$ & $\mathrm{~g} 080122$ & $\mathrm{~g} 160122$ \\
$\mathrm{a} 060123$ & $\mathrm{a} 120123$ & $\mathrm{~b} 070123$ & $\mathbf{b} 140123$ & $\mathrm{~g} 080123$ & $\mathrm{~g} 160123$ \\
$\mathrm{a} 060133$ & & $\mathrm{~b} 070133$ & & $\mathrm{~g} 080133$ & \\
$\mathbf{a 0 6 0 3 2 2}$ & $\mathrm{a} 120322$ & $\mathrm{~b} 070322$ & $\mathrm{~b} 140322$ & $\mathrm{~g} 080322$ & $\mathrm{~g} 160322$ \\
$\mathrm{a} 060323$ & $\mathrm{a} 120323$ & $\mathrm{~b} 070323$ & $\mathrm{~b} 140323$ & $\mathrm{~g} 080323$ & $\mathrm{~g} 160323$ \\
$\mathrm{a} 060333$ & & $\mathrm{~b} 070333$ & & $\mathrm{~g} 080333$ & \\
$\mathrm{a} 060622$ & $\mathrm{a} 120622$ & $\mathrm{~b} 070622$ & $\mathrm{~b} 140622$ & $\mathrm{~g} 080622$ & $\mathrm{~g} 160622$ \\
$\mathrm{a} 060623$ & $\mathrm{a} 120623$ & $\mathrm{~b} 070623$ & $\mathrm{~b} 140623$ & $\mathrm{~g} 080623$ & $\mathrm{~g} 160623$ \\
$\mathrm{a} 060633$ & & $\mathrm{~b} 070633$ & & $\mathrm{~g} 080633$ & \\
$\mathrm{a} 060922$ & $\mathrm{a} 120922$ & $\mathrm{~b} 070922$ & $\mathrm{~b} 140922$ & $\mathrm{~g} 080922$ & $\mathrm{~g} 160922$ \\
$\mathrm{a} 060923$ & $\mathrm{a} 120923$ & $\mathrm{~b} 070923$ & $\mathrm{~b} 140923$ & $\mathrm{~g} 080923$ & $\mathrm{~g} 160923$ \\
a060933 & & b070933 & & $\mathrm{g} 080933$ & \\
\hline
\end{tabular}

The purpose of this study is to acquire general information on the whole set of structures and about their different characteristics rather than to analyze individual structures in detail. We will perform: (i) analysis of energies obtained by different methods. (ii) conformations obtained by 'static' methods (MM and MDM, see computational details). (iii) conformations derived from MD simulations. (iv) relative stability and analyses of energy distributions within groups of isomers of connectivity (rows or columns in Table 1). (v) analyses of the rigidity, and the modes of structural deformations.

\section{Computational details}

In principle, any of the existing methods can be used for the purpose of the study: ab initio MO, semi-empirical MO, DFT, ${ }^{16,17}$ and molecular mechanics. ${ }^{18,19}$ The main disadvantage of the quantum mechanical methods is the enormous amount of computer time required for such a study, whilst methods utilizing molecular mechanics force fields (molecular mechanics minimization, molecular dynamics or Monte Carlo simulations) are the preferred alternative for problems of these dimensions. The MM3* force field, ${ }^{20}$ implemented in the molecular mechanics modeling package Macromodel 5.0, was used. Initial structures were generated with 
the graphical software. Three different protocols for finding low-energy conformations were compared: $^{21}$ (i) molecular mechanics energy minimization (MM); (ii) molecular dynamics simulations (MD); ${ }^{22}$ and (iii) geometry optimization of snapshots taken from the MD trajectories (MDM). The X-Cluster 1.2 (1995) program $^{23}$ implemented in Macromodel 5.0 was used to superimpose structures from the MD trajectories to obtain families of conformations (clusters) in each case. A total of 5000 iterations of conjugate gradient minimization PRCG $^{24}$ were allowed to be executed to optimize the geometries with a criterion for convergence of $0.05 \mathrm{~kJ} \mathrm{~mol}^{-1} \AA^{-1}$. The MD simulations ( $5 \mathrm{~ns}$ ) were carried out at $298 \mathrm{~K}$ with time-step $1.0 \mathrm{fs}$ and $\mathrm{SHAKE}^{25}$ activated in order to restrict movements of hydrogen atoms. The simulated systems were connected to a thermal bath ${ }^{26}$ for $0.2 \mathrm{ps}$. The stability of energy was attained within the $5.0 \mathrm{~ns}$ simulation except for a060622, b070122, and b070123. Additional $6.0 \mathrm{~ns}$ simulations were also not enough for the three cases listed above, which needed additional runs of $10.0 \mathrm{~ns}$ (giving a total of $21 \mathrm{~ns}$ ).

\section{Results and Discussion}

\section{Clustering analysis}

In addition to the energetic and geometrical information obtained from the MD simulations (see below), the cluster analyses provided the most representative structures. In general, three glycosidic oxygen atoms from each $\mathrm{CD}$ were used as representative atoms in the cluster analyses of conformations. However, all atoms were used for the carcerands of higher flexibility, when the bridging methylenic chains were of lengths 6 or 9. The RMSD criterion with superposition and the first structure in the trajectory file as a reference structure were adopted in a singlelinkage (nearest-neighbor) ascending clustering. Good clustering resulted only in eleven cases, i.e., $18 \%$ of the carcerands. We thus proceeded with analyzing the optimized structures extracted from the MD trajectories (MDM). About one hundred snapshots were collected for each carcerand and were afterwards minimized by MM. The subsequent clustering analysis produced good clustering for 52 carcerands, i.e., $87 \%$ of the cases. The clustering analyses for the remaining eight cases (marked as bold in Table 1) were also improved although no clear clustering was obtained.

Thus we conclude that the representative structures could be obtained from clustering analysis after MM minimization of about one hundred snapshots collected from the MD simulation trajectories but not from direct clustering of the MD trajectory.

\section{A comparative analysis of data from the MM, MD, and MDM studies}

The analysis of the MD trajectories provided us with a general view of the structural deformations of the carcerands as a whole. These deformations along the main molecular axis can be grouped into four types (I-IV): stretch, torsion, double anti-symmetric stretching/compression, and perpendicular sliding (Figure 4). Modes II and IV are coupled with mode I and also result at a closer approach of the 'heads' of the two CDs. 

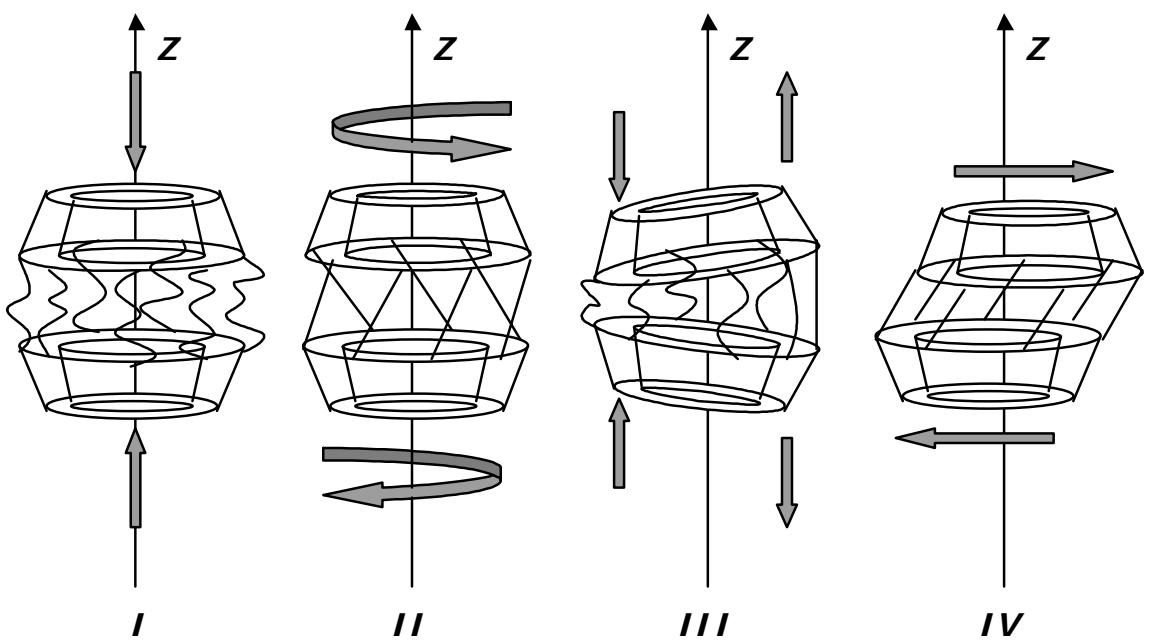

Figure 4. Modes of overall structural deformations of the carcerands along the main molecular axis. I, stretching and compression; II, torsion; III, double anti-symmetric stretching/compression; IV, perpendicular sliding.

MM total steric energies do not have physical meaning but they can serve to deduce general trends in variations of the energies obtained by different methods, as well as for the weights of the more important energy contributions. The MD simulations provide an average total energy, but for the sake of comparison with the structures from MM and MDM, the potential energy (without minimization) for the most representative structure obtained in the clustering analysis of the whole trajectory (see above) was used. For the MDM case, the energy of the representative structures obtained from cluster analysis was used (only one for each carcerand). The representative structure of each carcerand depends of the method used. A geometrical criterion (rms for overlapping) was used to obtain the representative conformations from the MD and MDM methods. This indicates that the conformations accessible for the molecule during the simulation are closely grouped, but they are not always the ones of the lowest energy.

In general, the energies are ordered $\mathrm{E}_{\mathrm{MD}}>\mathrm{E}_{\mathrm{MM}}>\mathrm{E}_{\mathrm{MDM}}$. The MM and MDM energies do not differ appreciably for carcerands with one bridge per glucose unit, owing to its limited flexibility. In contrast, and as expected because the systems were not minimized, the MD energies are higher.

The representative conformations obtained by the three methods appear similar when the shape is considered. Figure 5 displays the case of g160623, as an example, and the structure has predominantly a globular form according to MD and MDM, whilst MM displays a tendency for deformational mode IV. Cavities were present in all cases and this indicates that they are preserved during the simulation. Some bridges entered slightly into the cavities (Figure 5, view from the top for MD and MDM) as a consequence of the increased density of the chains and the concomitant repulsion between them. Typical examples for these 'hindered' cavities are the 
most "flexible" carcerands: the largest CDs with two bridges per glucose unit, and the longest methylenic bridges. The shapes of the cavities are not cylindrical but rather resemble spheroids.
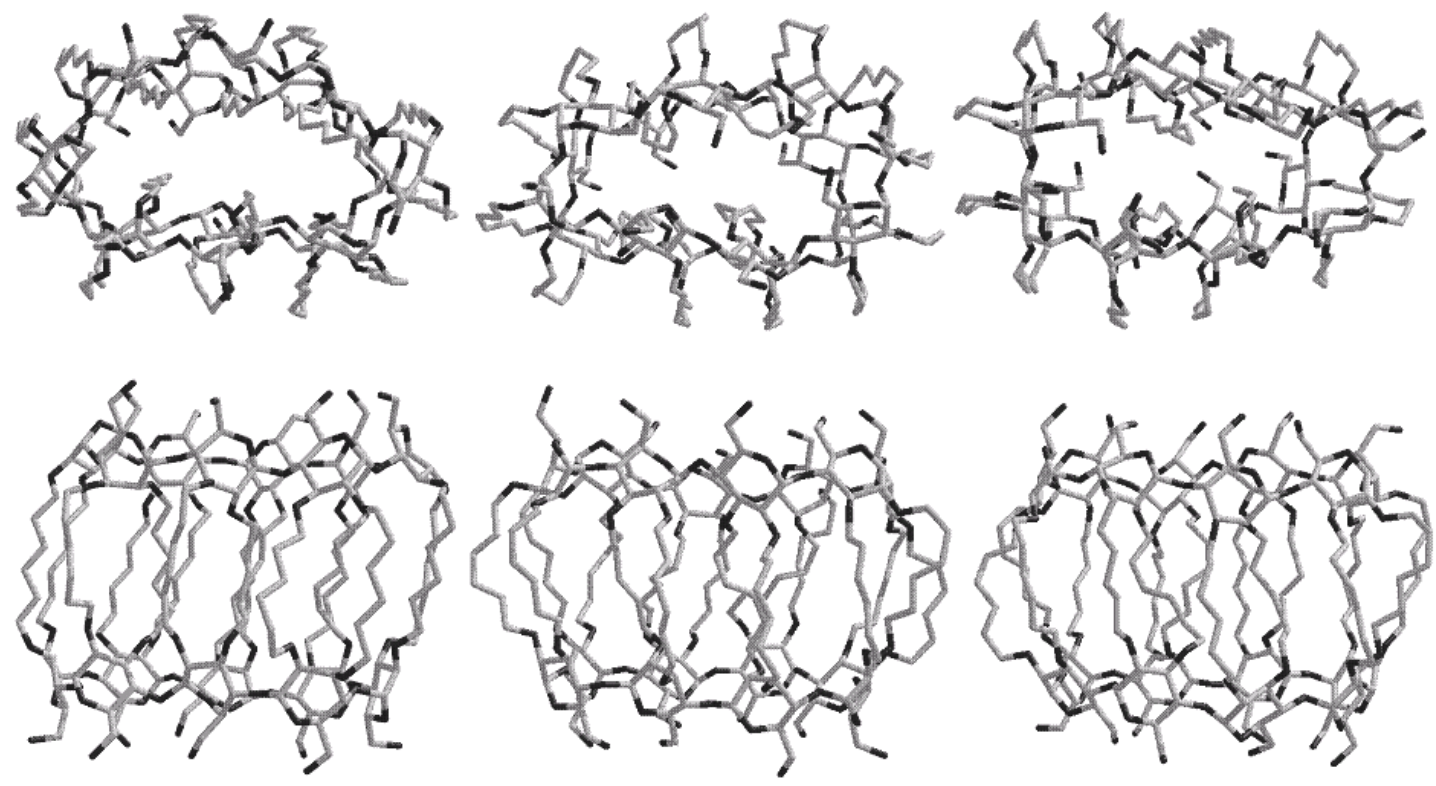

MM

DM

MDM

Figure 5. Top- and side views for the representative conformations of g160623 as obtained with the MM, MD, and MDM methods.

Carcerands formed by the same CD and by bridges with the same length have different numbers of 'connectivity isomers' (they have the same number and type of atoms) - three if the number of linkages per glucose is one (e.g. a060122, a060123, and a060133), and two if there are two. A tendency is evident for the one-bridge isomers, irrespective of the method usednamely, isomers 22 have lower energy than isomers 33. With few exceptions (a0601, a0603, and b0701) the energies of the three isomers are in the order $22<23<33$. In general, isomers with one bridge per glucose residue present similar energetic characteristics. The analysis of the energy terms indicates that the contribution from the angle-bending term raises the MD energies. Except for the electrostatic term, which increases in the order $22<23<33$, all other energy contributions present relatively constant values.

In isomers with two bridges per glucose unit, the bending potentials again contribute to the higher total energies estimated with MD. Although to a lesser extent, the van der Waals interactions also donate in the same direction, while all other energy terms remained practically the same (see Table 2). 
Table 2. Energy data for the connectivity isomers of carcerand g1609 as obtained by the three different methods used in this study

\begin{tabular}{lcccccc}
\hline & \multicolumn{2}{c}{ MM } & \multicolumn{2}{c}{ DM } & \multicolumn{2}{c}{ MDM } \\
\cline { 2 - 7 } g1609 & $\mathbf{2 2}$ & $\mathbf{2 3}$ & $\mathbf{2 2}$ & $\mathbf{2 3}$ & $\mathbf{2 2}$ & $\mathbf{2 3}$ \\
E(total) & 3260.1 & 3476.5 & 4709.3 & 4751.6 & 2915.7 & 2947.9 \\
E(str) & 176.6 & 189.7 & 176.6 & 189.7 & 154.5 & 156.3 \\
E(bend) & 626.1 & 715.2 & 1815.1 & 1816.0 & 475.2 & 528.6 \\
E(tors) & 511.6 & 593.9 & 567.5 & 600.8 & 438.9 & 459.5 \\
E(str-bend) & 36.3 & 39.6 & 35.5 & 38.7 & 31.9 & 32.2 \\
E(bend-bend) & 5.9 & 8.3 & 56.9 & 59.1 & 1.5 & 2.4 \\
E(tors-str) & -29.2 & -35.1 & -27.7 & -30.9 & -24.6 & -24.8 \\
E(vdW) & 1206.8 & 1225.0 & 1365.9 & 1367.6 & 1149.7 & 1151.6 \\
E(elec) & 733.9 & 747.8 & 726.3 & 727.0 & 694.3 & 654.8 \\
E(h-bond) & -7.8 & -8.0 & -6.8 & -16.3 & -5.6 & -12.6 \\
\hline
\end{tabular}

\section{Discussion of the method used}

There was specific reasoning for utilizing simultaneously three different methodologies (MM. MD, and MDM). It is well known that the MM minimization approach, when applied to large molecules, does not guarantee success in searching for the global minimum conformation. To bypass this problem, extensive parts of the potential-energy hypersurface can be explored (and energetically stable structures are searched) through molecular dynamics simulations, but only very large simulation times can sample a large enough phase-space of the macromolecule. It is also worth stressing, that as a consequence of the importance of temperature. the states obtained from the MD simulations are not the same as those derived by direct minimization approaches. Finally, when optimizing geometries of snapshots picked up from MD trajectories (MDM). Local minima are obtained. They represent structures about which molecular geometries fluctuate during the time evolution of the simulated system. Significant parts of the sampled energy surface are disregarded, and the MDM protocol is less representative. The populations of the MDM minima depend on the number of structures sampled in the vicinity of these minima and their energies. All carcerands comply with this behavior, except for a060323. b070622. and b140123. We shall now try to explain the reasons for these deviations.

Carcerand a060323 presents a case where the MM and the MDM representative conformations coincide (all individual energy contributions are exactly the same). As a rule, lower energies were usually obtained for the MDM conformations because a larger number of candidate structures was explored. The trajectory traversed preferentially portions of the phasespace about the MM minimum and there is nothing strange in the fact that this has happened.

In contrast, the MM energy of b070622 is slightly lower than its MDM energy. A reasonable explanation is that a geometrical criterion (not an energy criterion) was used to select structures when the geometries sampled in the trajectory files were subjected to cluster analysis. A larger 
cluster (represented by a larger number of conformations) does not necessarily mean that this cluster contains the structure of the lowest energy. What has happened in this case is that during the MD simulation the trajectory remained for a longer time about a minimum of higher energy than in the vicinity of the MM structure of lower energy. After minimization, the whole group of structures that predominated in number (the largest MD cluster) converged to the most representative MDM conformation (the largest MDM cluster).

In the third case, b140123, the energy of the MM structure is much higher not only in comparison with the energy of the MDM representative conformation. but also compared with the energy of the MD cluster. This is rather surprising; the MM energy is the one that deviates from the general trend. We concluded that the MM optimized structure was too far from the lower energy minimum. After direct MM optimization, a minimum was obtained that is closer to the starting geometry and above the lowest-energy minima region. Its bending contribution is practically the same as that estimated with MD. During the MD simulation, lower energy portions were sampled for longer times, and the trajectory fluctuated preferentially about such minima. After minimizing the sampled structures (MDM), the representative structure about which the molecule used to oscillate was obtained. The present case is a good illustration of the limitations of the MM methodology for exploring efficiently the conformational space of large molecules. Alternatively, this is a case where the formation of intramolecular hydrogen bonds is of crucial importance for the energy stabilization of the representative conformations. The MM minimization yielded the closest local minimum. During the MD simulation, however, the allowed intramolecular dynamical motions resulted at the more favorable orientations of bonds for hydrogen-bond formation. Unfavorable angle- bending deformations introduced in the MM structure were avoided after optimization of snapshots taken from the MD trajectory file.

\section{Summary of energy data}

As we emphasized at the beginning of the analysis, the relative stability of molecules with different numbers and types of atoms cannot be extracted from the total steric energies. To avoid this problem the contributions of individual energy terms, given in percentages as normalized relative to the total steric energies, will be analyzed. Such an approach is not completely adequate either, because the different atom types in the larger carcerands do not increase proportionally, e.g., b070122 and b140922 have the same number of oxygen atoms. but b140922 has 119 carbon atoms in excess. For brevity, only the $\beta$-carcerands will be considered; their values are shown in Table 3. All conclusions are valid for the other two types of CDcarcerands as well. The normalization preserved the negative values for the stabilizing energy terms. 
Table 3. Contributions of individual energy terms in $\beta$-carcerands relative to the total energy

\begin{tabular}{|c|c|c|c|c|c|c|c|c|c|c|c|c|}
\hline \multirow[t]{2}{*}{ MM } & \multicolumn{3}{|c|}{ b0701 } & \multicolumn{3}{|c|}{$\mathrm{b} 0703$} & \multicolumn{3}{|c|}{ b0706 } & \multicolumn{3}{|c|}{ b0709 } \\
\hline & 22 & 23 & 33 & 22 & 23 & 33 & 22 & 23 & 33 & 22 & 23 & 33 \\
\hline $\mathrm{E}$ (total) & 100.0 & 100.0 & 100.0 & 100.0 & 100.0 & 100.0 & 100.0 & 100.0 & 100.0 & 100.0 & 100.0 & 100.0 \\
\hline $\mathrm{E}$ (str) & 5.9 & 5.8 & 5.2 & 5.1 & 5.0 & 5.0 & 5.6 & 4.9 & 4.7 & 5.1 & 5.1 & 4.9 \\
\hline $\mathrm{E}$ (bend) & 20.2 & 19.9 & 15.9 & 14.8 & 15.2 & 15.5 & 14.1 & 15.4 & 16.1 & 14.7 & 13.3 & 14.6 \\
\hline $\mathrm{E}$ (tors) & 9.3 & 6.2 & 8.9 & 11.8 & 9.1 & .1 & 7.4 & 7.7 & 8.4 & 11.4 & 7.7 & 7.9 \\
\hline $\mathrm{E}$ (str-bend) & 1.0 & 0.9 & 0.8 & 0.9 & 0.8 & 0.8 & 0.9 & 0.9 & 0.9 & 0.9 & 0.9 & 0.9 \\
\hline $\mathrm{E}$ (bend-bend & 0.2 & 0.1 & 0.1 & 0.0 & 0.0 & 0.1 & 0.0 & 0.1 & 0.2 & 0.1 & 0.1 & 0.1 \\
\hline $\mathrm{E}$ (tors-str) & -0.9 & -0.8 & -0.8 & -0.8 & -0.7 & -0.7 & -0.7 & -0.7 & -0.7 & -0.8 & -0.7 & -0.6 \\
\hline $\mathrm{E}(\mathrm{vdW})$ & 45.2 & 43.9 & 42.0 & 43.5 & 40.8 & 38.9 & 49.9 & 40.9 & 36.9 & 45.4 & 45.9 & 40.5 \\
\hline $\mathrm{E}(\mathrm{elec})$ & 20.4 & 25.1 & 29.5 & 26.4 & 31.2 & 33.3 & 24.5 & 31.8 & 33.9 & 24.4 & 28.9 & 32.5 \\
\hline E(h-bon & -1.4 & -1.2 & -1.6 & -1.6 & -1.4 & -1.0 & -1.6 & -0.9 & -0.5 & -1.2 & -1.2 & -0.7 \\
\hline \multirow[t]{2}{*}{ MD } & \multicolumn{3}{|c|}{ b0701 } & \multicolumn{3}{|c|}{ b0703 } & \multicolumn{3}{|c|}{ b0706 } & \multicolumn{3}{|c|}{ b0709 } \\
\hline & 22 & 23 & 33 & 22 & 23 & 33 & 22 & 23 & 33 & 22 & 23 & 33 \\
\hline $\mathrm{E}$ (total) & 100.0 & 100.0 & 100.0 & 100.0 & 100.0 & 100.0 & 100.0 & 100.0 & 100.0 & 100.0 & 100.0 & 100.0 \\
\hline $\mathrm{E}(\mathrm{str})$ & 4.5 & 4.2 & 3.9 & 3.7 & 3.7 & 3.7 & 3.7 & 3.6 & 3.5 & 3.5 & 3.4 & 3.4 \\
\hline $\mathrm{E}$ (bend) & 37.0 & 32.3 & 31.4 & 32.8 & 33.3 & 27.0 & 30.4 & 32.5 & 33.3 & 35.0 & 34.0 & 37.0 \\
\hline $\mathrm{E}$ (tors) & 6.1 & 7.2 & 3 & 8.0 & 8.4 & 9.0 & 8.8 & 7.9 & 6.8 & 7.3 & 8.3 & 6.4 \\
\hline $\mathrm{E}$ (str-bend) & 0.8 & 0.7 & 0.6 & 0.6 & 0.6 & 0.6 & 0.6 & 0.7 & 0.6 & 0.6 & 0.6 & 0.7 \\
\hline $\mathrm{E}$ (bend-be & 1.0 & 0.9 & 1.0 & 1.0 & 1.0 & 0.8 & 0.9 & 1.0 & 1.0 & 1.2 & 1.0 & 1.2 \\
\hline E(tors- & -0.7 & -0.7 & -0.6 & -0.6 & -0.7 & -0.6 & -0.7 & -0.6 & -0.5 & -0.5 & -0.6 & -0.5 \\
\hline $\mathrm{E}(\mathrm{vdW})$ & 36.7 & 33.7 & 32.2 & 31.9 & 32.2 & 31.0 & 33.0 & 31.9 & 30.4 & 34.5 & 30.8 & 28.9 \\
\hline $\mathrm{E}(\mathrm{elec})$ & 15.5 & 22.5 & 25.0 & 23.3 & 22.4 & 29.1 & 24.1 & 23.7 & 25.4 & 19.3 & 23.1 & 23.6 \\
\hline E(h-bon & -0.9 & -0.8 & -0.9 & -0.9 & -0.9 & -0.5 & -0.8 & -0.7 & -0.5 & -0.8 & -0.7 & -0.6 \\
\hline \multirow[t]{2}{*}{ MDM } & \multicolumn{3}{|c|}{ b0701 } & \multicolumn{3}{|c|}{ b0703 } & \multicolumn{3}{|c|}{ b0706 } & \multicolumn{3}{|c|}{ b0709 } \\
\hline & 22 & 23 & 33 & 22 & 23 & 33 & 22 & 23 & 33 & 22 & 23 & 33 \\
\hline $\mathrm{E}$ (total) & 100.0 & 100.0 & 100.0 & 100.0 & 100.0 & 100.0 & 100.0 & 100.0 & 100.0 & 100.0 & 100.0 & 100.0 \\
\hline $\mathrm{E}$ (str) & 6.5 & 6.1 & 5.6 & 5.2 & 5.0 & 5.1 & 5.1 & 5.0 & 5.1 & 5.4 & 5.2 & 5.1 \\
\hline E(bend) & 21.7 & 17.8 & 15.8 & 13.7 & 14.6 & 15.3 & 11.0 & 13.4 & 16.2 & 16.2 & 13.9 & 16.0 \\
\hline $\mathrm{E}$ (tors) & 6.9 & 6.9 & 9.3 & 10.5 & 10.3 & 7.9 & 9.5 & 6.9 & 6.2 & 6.0 & 6.8 & 5.0 \\
\hline E(str-bend & 1.1 & 1.0 & 0.8 & 0.9 & 0.9 & 0.9 & 0.8 & 0.9 & 0.9 & 1.0 & 0.9 & 0.9 \\
\hline E(bend-bend) & 0.3 & 0.1 & 0.1 & 0.0 & 0.0 & 0.1 & -0.1 & 0.0 & 0.1 & 0.1 & 0.0 & 0.1 \\
\hline E(tors-str) & -1.0 & -0.9 & -0.9 & -0.8 & -0.8 & -0.7 & -0.8 & -0.7 & -0.8 & -0.6 & -0.7 & -0.7 \\
\hline $\mathrm{E}(\mathrm{vdW})$ & 50.4 & 46.6 & 41.1 & 45.9 & 41.1 & 38.1 & 45.5 & 42.1 & 37.6 & 48.1 & 44.7 & 40.6 \\
\hline $\mathrm{E}(\mathrm{elec})$ & 16.2 & 24.0 & 29.5 & 26.5 & 30.3 & 34.1 & 30.6 & 33.5 & 35.3 & 25.2 & 30.2 & 33.6 \\
\hline $\mathrm{E}$ (h-bond) & -2.0 & -1.5 & -1.3 & -1.8 & -1.3 & -0.7 & -1.7 & -1.1 & -0.7 & -1.4 & -1.1 & -0.7 \\
\hline
\end{tabular}




\begin{tabular}{|c|c|c|c|c|c|c|c|c|}
\hline \multirow[t]{2}{*}{ MM } & \multicolumn{2}{|c|}{ b1401 } & \multicolumn{2}{|c|}{ b1403 } & \multicolumn{2}{|c|}{ b1406 } & \multicolumn{2}{|c|}{ b1409 } \\
\hline & 22 & 23 & 22 & 23 & 22 & 23 & 22 & 23 \\
\hline $\mathrm{E}$ (total) & 100.0 & 100.0 & 100.0 & 100.0 & 100.0 & 100.0 & 100.0 & 100.0 \\
\hline $\mathrm{E}(\mathrm{str})$ & 5.7 & 6.8 & 5.3 & 5.5 & 5.5 & 5.8 & 5.9 & 5.8 \\
\hline$E$ (bend) & 28.2 & 30.7 & 20.7 & 22.5 & 19.9 & 20.6 & 19.0 & 23.3 \\
\hline$E$ (tors) & 8.7 & 8.4 & 18.9 & 16.4 & 15.8 & 16.2 & 14.6 & 11.3 \\
\hline $\mathrm{E}$ (str-bend) & 1.0 & 1.1 & 1.0 & 1.1 & 1.0 & 1.2 & 1.1 & 1.1 \\
\hline $\mathrm{E}$ (bend-bend) & 0.4 & 1.1 & 0.2 & 0.2 & 0.2 & 0.2 & 0.2 & 0.3 \\
\hline $\mathrm{E}$ (tors-str) & -0.9 & -0.9 & -1.1 & -1.1 & -1.0 & -1.1 & -0.9 & -0.8 \\
\hline $\mathrm{E}(\mathrm{vdW})$ & 39.5 & 35.2 & 35.5 & 35.8 & 37.3 & 38.0 & 37.6 & 35.5 \\
\hline E(elec) & 17.7 & 17.7 & 19.7 & 19.8 & 21.7 & 19.5 & 22.7 & 23.6 \\
\hline E(h-bond) & -0.3 & -0.1 & -0.3 & -0.2 & -0.3 & -0.5 & -0.2 & -0.1 \\
\hline \multirow[t]{2}{*}{$\mathrm{MD}$} & \multicolumn{2}{|c|}{ b1401 } & \multicolumn{2}{|c|}{ b1403 } & \multicolumn{2}{|c|}{ b1406 } & \multicolumn{2}{|c|}{ b1409 } \\
\hline & 22 & 23 & 22 & 23 & 22 & 23 & 22 & 23 \\
\hline $\mathrm{E}$ (total) & 100.0 & 100.0 & 100.0 & 100.0 & 100.0 & 100.0 & 100.0 & 100.0 \\
\hline $\mathrm{E}(\mathrm{str})$ & 4.5 & 7.4 & 4.2 & 4.5 & 4.0 & 4.3 & 4.1 & 4.2 \\
\hline $\mathrm{E}$ (bend) & 43.9 & 34.6 & 36.3 & 36.5 & 37.4 & 34.8 & 40.7 & 40.4 \\
\hline $\mathrm{E}$ (tors) & 5.3 & 10.8 & 14.4 & 13.5 & 12.2 & 14.4 & 10.2 & 9.4 \\
\hline $\mathrm{E}$ (str-bend) & 0.9 & 0.9 & 0.8 & 0.9 & 0.7 & 0.7 & 0.8 & 0.8 \\
\hline E(bend-bend) & 1.1 & 0.9 & 1.1 & 1.0 & 1.2 & 1.1 & 1.3 & 1.4 \\
\hline $\mathrm{E}$ (tors-str) & -0.7 & -1.1 & -0.8 & -0.8 & -0.7 & -0.8 & -0.6 & -0.5 \\
\hline $\mathrm{E}(\mathrm{vdW})$ & 31.3 & 31.6 & 27.6 & 29.6 & 28.8 & 30.2 & 28.5 & 28.8 \\
\hline $\mathrm{E}(\mathrm{elec})$ & 14.0 & 15.4 & 16.6 & 15.3 & 16.5 & 15.3 & 15.2 & 15.6 \\
\hline E(h-bond) & -0.2 & -0.4 & -0.2 & -0.4 & -0.1 & -0.1 & -0.2 & -0.1 \\
\hline \multirow[t]{2}{*}{ MDM } & \multicolumn{2}{|c|}{ b1401 } & \multicolumn{2}{|c|}{ b1403 } & \multicolumn{2}{|c|}{ b1406 } & \multicolumn{2}{|c|}{ b1409 } \\
\hline & 22 & 23 & 22 & 23 & 22 & 23 & 22 & 23 \\
\hline $\mathrm{E}$ (total) & 100.0 & 100.0 & 100.0 & 100.0 & 100.0 & 100.0 & 100.0 & 100.0 \\
\hline $\mathrm{E}(\mathrm{str})$ & 5.6 & 5.8 & 5.5 & 5.8 & 5.4 & 5.5 & 5.5 & 5.6 \\
\hline$E$ (bend) & 31.9 & 21.5 & 20.0 & 20.3 & 17.1 & 17.9 & 17.9 & 17.7 \\
\hline $\mathrm{E}$ (tors) & 6.3 & 14.3 & 17.6 & 17.8 & 15.2 & 15.3 & 11.2 & 11.3 \\
\hline $\mathrm{E}($ str-bend $)$ & 1.1 & 1.0 & 1.0 & 1.0 & 1.0 & 1.0 & 1.1 & 1.1 \\
\hline E(bend-bend) & 0.4 & 0.1 & 0.1 & 0.1 & 0.0 & 0.1 & 0.1 & 0.1 \\
\hline $\mathrm{E}$ (tors-str) & -0.9 & -1.3 & -1.1 & -1.2 & -0.9 & -0.9 & -0.7 & -0.8 \\
\hline$E(v d W)$ & 38.7 & 40.3 & 37.9 & 38.8 & 38.9 & 38.8 & 41.9 & 40.9 \\
\hline $\mathrm{E}$ (elec) & 17.1 & 18.8 & 19.3 & 17.7 & 23.5 & 22.5 & 23.1 & 24.3 \\
\hline E(h-bond) & -0.2 & -0.3 & -0.2 & -0.3 & -0.2 & -0.3 & -0.2 & -0.2 \\
\hline
\end{tabular}


From the analysis of the data in Table 3 the following trends were deduced: (i) the van der Waals, electrostatic, bending and torsion terms are the main energy contributors, ca., 90\%; (ii) bending deformations have very high weight for the MD representative structures, although differences exist in the distributions among carcerands with one and two bridges per glucose unit (for one bridge per glucose, MM and MDM representative conformations have bending energy to contribute less than the non-bonded terms, whilst bending and van der Waals energies have the highest and equal weight: for two bridges per glucose, their higher rigidity produces the highest bending energy values for MM and MDM conformations. and the bending contributions prevail significantly over the other energy terms for the MD): (iii) the variation of the van der Waals curve opposes the concomitant electrostatic energy contributions (although not so clearly expressed, such behavior also characterizes the pair bending/torsion terms). ${ }^{1 \mathrm{c}}$ Although the variations are fairly symmetrical, percentage electrostatic energy variations are more significant than the variations of the van der Waals interactions; (iv) irrespective of the type of CD, more properties in common are seen when the carcerands are sorted according to the number of bridges per glucose residue than when they are grouped according to the length of the bridges.

\section{Summary of structural data}

The structural data are now analyzed in terms of the flexibilities of the geometries, overall torsions, and shape, as functions of the size of the macromolecule.

\section{Carcerands with one bridge per glucose residue}

The carcerands differ in rigidity and shape. The smaller ones are more rigid, and preserve their geometries and open cavities during the MD simulation. With increase in the size of the CD and the length of the chains the structures become more flexible and the cavities are less accessible (see also Figure 6). A tendency for overall deformation mode IV exists. The $\alpha$ - and $\beta$ - carcerands with chain lengths 1 and 3 can be considered as rigid, whilst $\gamma-6$ and $\gamma-9$ are flexible. All other structures represent intermediate situations.

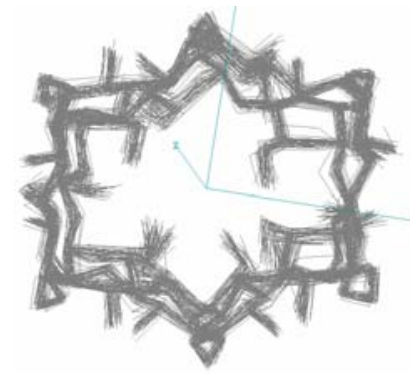

a06012

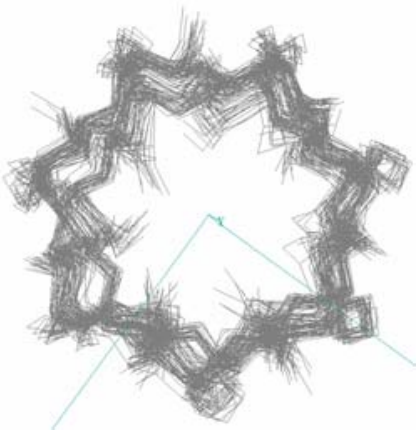

b070322

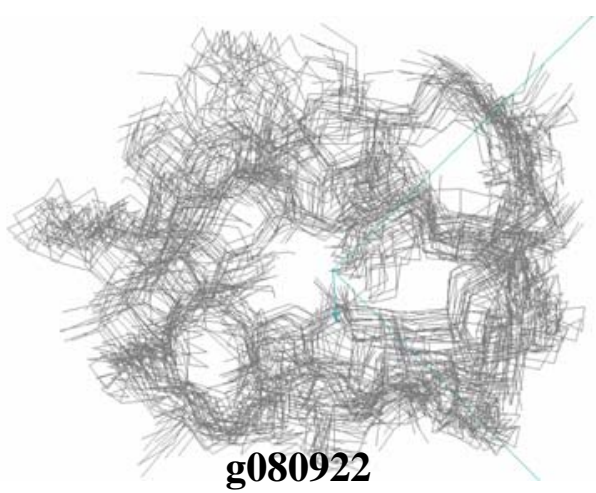

g080922

Figure 6. Top views of MD overlapped conformations for some selected carcerands. 
The number and the length of methylenic bridges are important for the properties of the carcerands. There is similarity in the deformations of the pairs of carcerands with one- and three methylene groups, as well as with six- and nine groups (Figure 7). Levo-oriented torsion of the CD positioned above with respect to the lower one is clearly seen (mode for overall structural deformation II). It depends on the isomerism of connectivity (Figure 8) and can be envisaged to result from a balance that minimizes strain in the methylenic bridges and optimizes intramolecular hydrogen bonding (Figure 9).

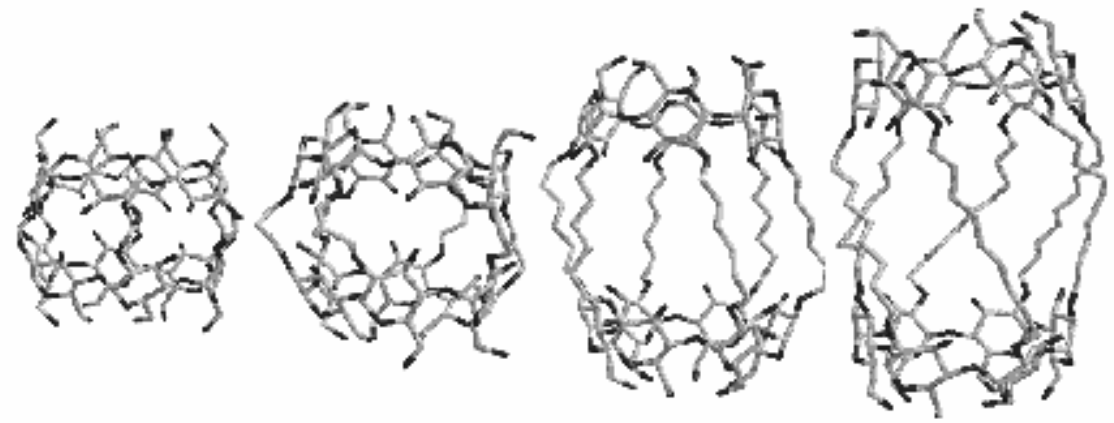

a) $\begin{array}{llll}\mathrm{a} 060122 & \mathrm{a} 060322 & \mathrm{a} 060622 & \mathrm{a} 060922\end{array}$

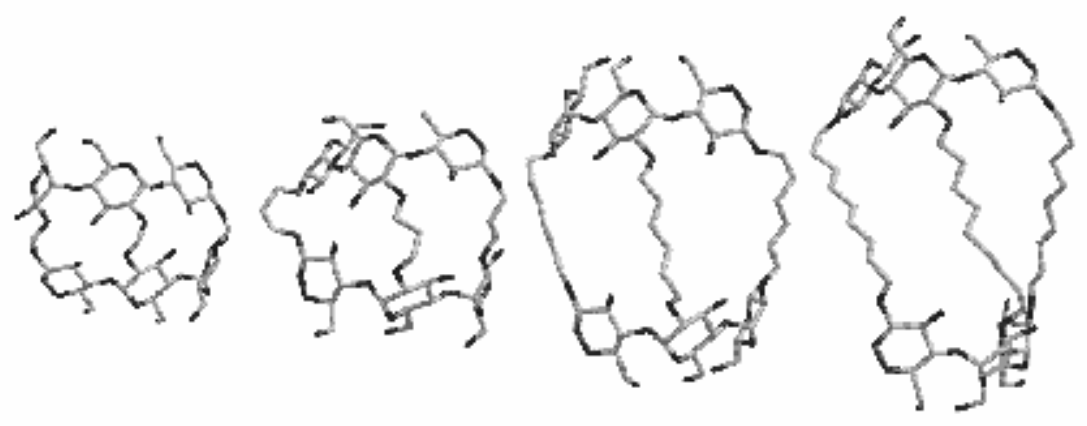

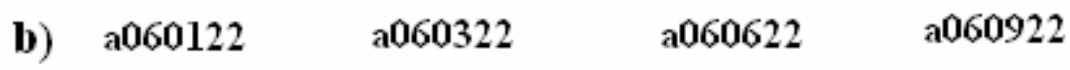

Figure 7. (a) Representative structures of all a06 isomers 22 obtained by MDM; (b) vertical cross-section.

Two types of hydrogen bonds are possible in small carcerands (Figure 9); between hydroxyls, and between hydroxyls or ether oxygens. These hydrogen bonds are not always formed, because with increase in the distance between the CDs (longer chains) the probability of hydrogen bonds being formed between hydroxyl groups of different CDs decreases. The detail in Figure 9 reveals the more pronounced disordered folding of isomers 23 compared with isomers 22 or 33 . The small carcerands have a globular shape. The semi-rigid $\alpha$ - and $\beta$-carcerands have preferentially cylindrical forms, whilst the largest ones of type $\gamma$ are significantly disordered, losing the cylindrical shape and resembling a spheroid (Figure 6). 


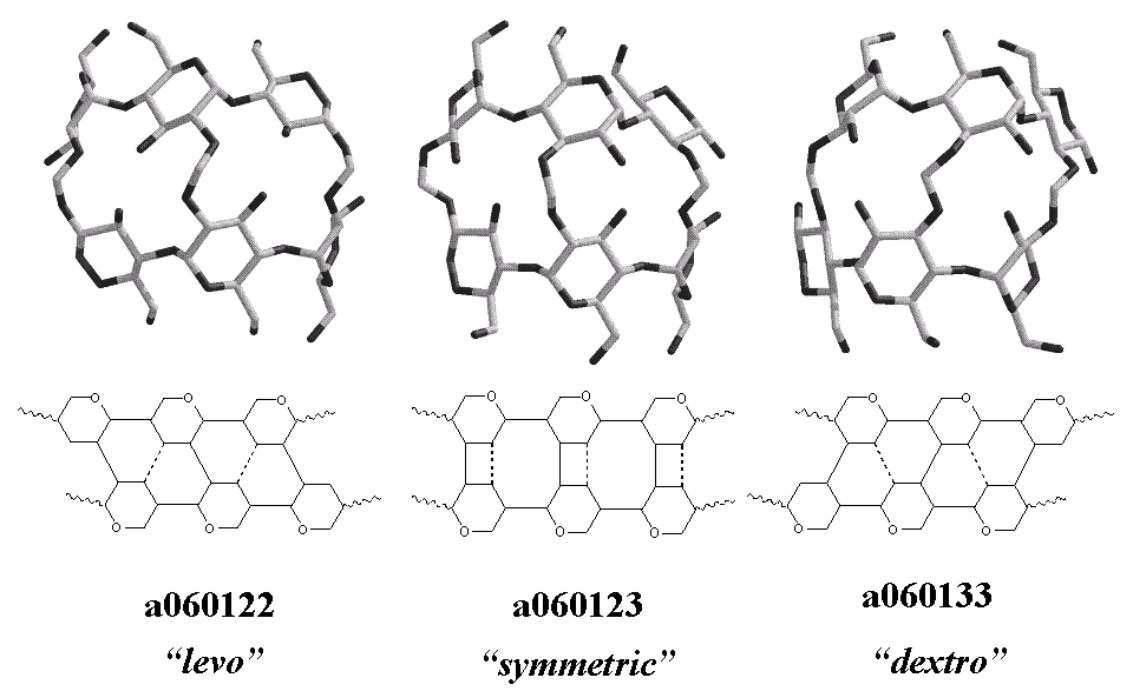

Figure 8. A vertical cross-section of representative structures of connectivity isomers 22, 23, and 33 of carcerand a0601 obtained with the MDM method.

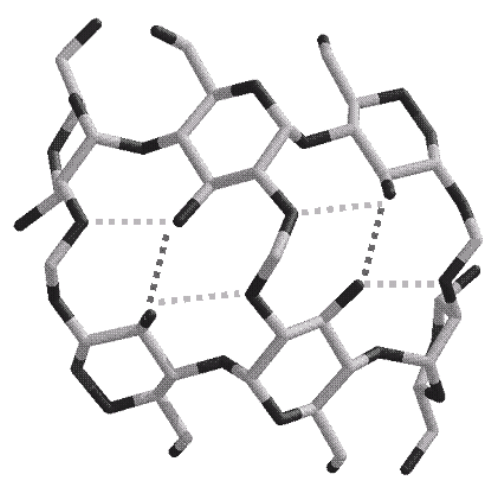

$\mathbf{a 0 6 0 1 2 2}$

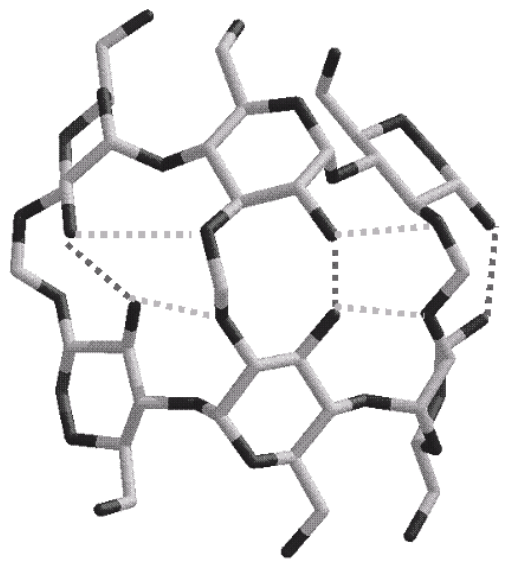

$\mathbf{a 0 6 0 1 2 3}$

Figure 9. A vertical cross-section of representative structures of connectivity isomers 22 and 23 of carcerand a0601 with hydrogen bonds given by dashed lines.

Perhaps the most important fact to emphasize is that there is a tendency for blocking the entrance to the cavity through closing the CDs with increase in the size of the carcerands. The overall deformations follow structural mode IV (Figure 10). At the same time (Figure 6) the methylenic chains start to enter the interior of the carcerands more frequently. 


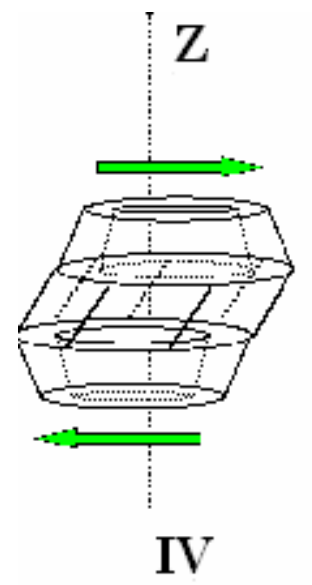

(a)

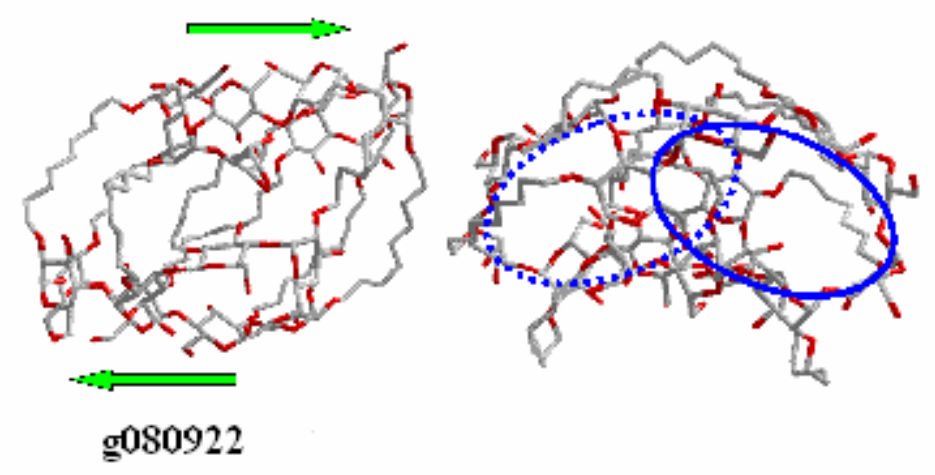

(b) (c)

Figure 10. (a) Schematic representation of the structural deformation mode IV. (b) side view of the MDM representative structure for carcerand g080922. c) top view of the same carcerand (the lower $\mathrm{CD}$ is marked as a dashed ellipse).

\section{Carcerands with two bridges per glucose residue}

Here again the $\alpha-1$ carcerand was of the highest rigidity. It kept stable conformation with an open cavity during the whole MD simulation. With increasing the size of the CDs and the length of the chains, more flexible became the structures. Now, however, the folding was not the same as observed for the one-bridged carcerands. The tendency for partial closure of the CDs was observed, but the large number of chains and the steric repulsion between them did not allow the methylenic groups to approach too close. Some bridges entered the cavities and gave the appearance for an increased inaccessibility (Figures 11). The larger number of chains and the repulsion between them were the factors that preserved the globular form of the large carcerands with the appearance of structural mode I (Figure 12) instead of folding into mode IV as observed before.

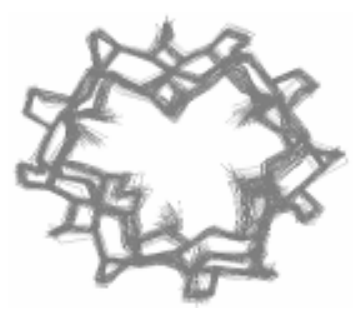

$\mathbf{a 1 2 0 1 2 2}$

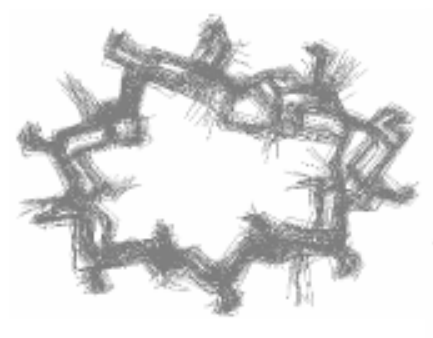

b140322

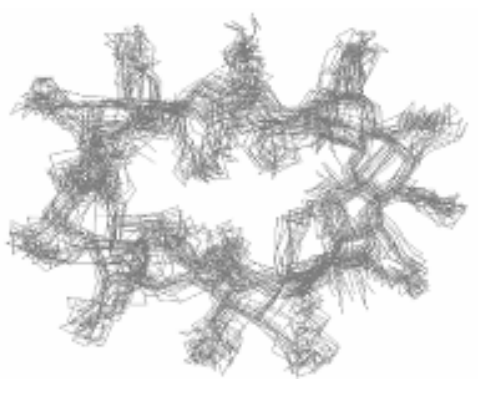

g160922

Figure 11. Side and top views of selected DM clustered conformations for some carcerands having two bridges per glucose. 
We have already stressed the importance of the interconnecting bridges for the structural characteristics such as flexibility. In this case, where their are two bridges per glucose residuedue to the type of the connection - there are only two possible isomers. The absence of hydroxyl groups in the interior region between the two CDs diminished the potential for overall torsion of the structures (Figure 13). There were no contributions from hydrogen bonding in this case. Because of the type of binding, isomer 22 maintained its most rigid form as the one of isomer 23 for the carcerands with bridges of lengths 1 and 3. This effect became weaker with increase in the length of the bridges as a result of the higher flexibility introduced.

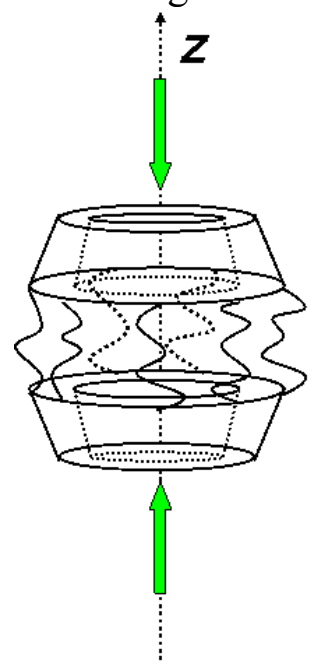

$\boldsymbol{I}$
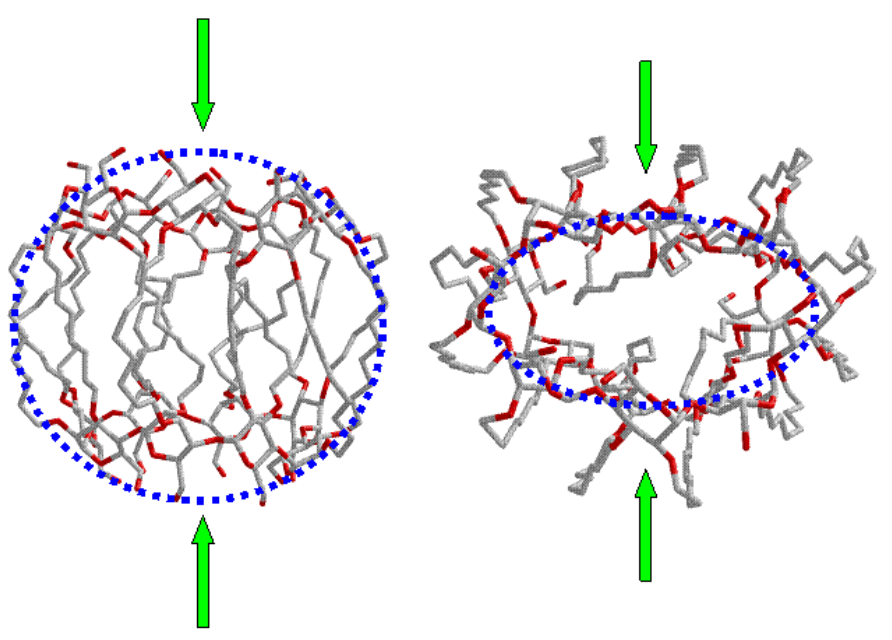

Figure 12. MDM structure of carcerand g160922. The globular form is maintained due to the chains and the partial blocking of the cavity from the sides of the CDs and the entrance of some chains in the cavity.

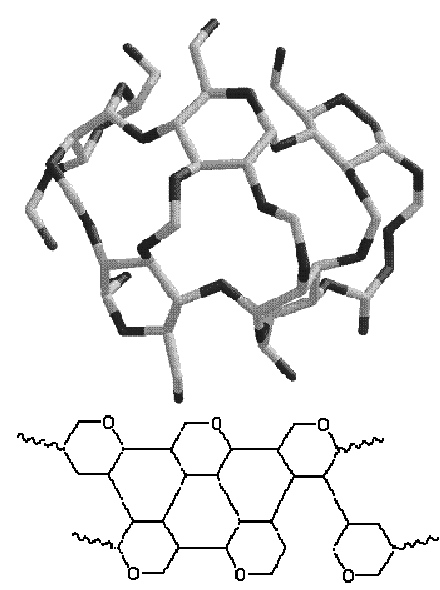

$\mathbf{a 1 2 0 1 2 2}$



$\mathbf{a 1 2 0 1 2 3}$

"symmetric"

Figure 13. Vertical cross-sections of the MDM structures of the two connectivity isomers 22 and 23 of carcerand $\mathbf{a 1 2 0 1 .}$ 


\section{Conclusions}

From the methodological point of view we can finally conclude that the minimization of snapshots from MD simulations is of practical advantage in the search of conformational energy minima and representative structures for large and flexible systems. The cluster analysis based on geometrical parameters (as the RMSD) was shown to be a good method for obtaining representative structures. However, the representative conformations obtained in this way differ from those calculated by using energy criteria.

The structures obtained from MD usually have higher energy than those from MM or MDM. The flexibility of the carcerands increases with increasing size of the $\mathrm{CD}$ and with the length of the chains. In general, the small carcerands are rigid and have spherical shapes. The larger carcerands are more flexible. their cavities are more hidden and they are spheroidal in shape. The carcerands with one bridge per glucose present "levo," symmetrical and "dextro" arrangements, owing to the hydrogen-bonds formed between the two CD units. while those with two bridges per glucose show only two conformations (symmetric and asymmetric). It is also worth noting that all the characteristics of the carcerands become more diffuse when the size of the cavity (related to the length of the chains) increases.

\section{Acknowledgements}

This work has been possible thanks to grants BQU2003-01231 from, "Ministerio de Ciencia y Tecnologia". Spain, and X-1406 from the National Science Foundation. Bulgaria. UAB is thanked for a fellowship to one of us (K.K.B.), and Sabbatical grants for P.M.I. are also acknowledged from the "Generalitat de Catalunya", Catalonia, Spain (Visiting Professorship) and the, "Ministerio de Educación, Cultura y Deportes," Spain.

\section{References}

1. (a) Redondo, J.; Jaime, C.; Virgili, A.; Sánchez-Ferrando, F. J. Molec. Struct. 1991, 28, 6521. (b) Sánchez-Ruiz, X.; Alvarez-Larena, A.; Jaime, C.; Piniella, J. F.; Redondo, J.; Virgili, A.; Sánchez-Ferrando, F.; Germain, G.; Baert, F. Supramol. Chem. 1999, 10, 219. (c) Jaime, C.; Redondo, J.; Sánchez-Ferrando. F.; Virgili, A. J. Org. Chem. 1990, 55, 4773. (d) Ivanov, P.; Jaime, C. An. Quím. Int. Ed. 1996, 92, 13. (e) Ivanov, P. M.; Jaime, C. J. Molec. Struct. 1996, 377, 137. (f) Ivanov, P.; Salvatierra, D.; Jaime, C. J. Org. Chem. 1996, 61, 7012. (g) Salvatierra, D.; Jaime, C.; Virgili, A.; Sánchez-Ferrando, F. J. Org. Chem. 1996, 61, 9578. (h) Zubiaur, M.; Jaime, C. J. Org. Chem. 2000, 65, 8139.

2. (a) Fotiadu, F.; Fathallah, M.; Jaime, C. J. Org. Chem. 1994, 59, 1288. (b) Pérez, F.; Jaime, C; Sánchez-Ruiz, X. J. Org. Chem. 1995, 60, 3840. (c) Cervelló, E.; Jaime, C. J. Molec. Struct. (THEOCHEM) 1998, 428, 195. (d) Cervelló, E.; Jaime, C. An. Quím. It. Ed. 1998, 45, 244. (e) Cervelló, E.; Mazzucchi, F.; Jaime, C. J. Molec. Struct. (THEOCHEM) 2000, 
530, 155. (f) Sánchez-Ruiz, X.; Ramos, M.; Jaime, C. J. Molec. Struct. 1998, 442, 93. (g) Fotiadu, F.; Fathallah, M.; Jaime, C. J. Inc. Phenom. 1993, 16, 55.

3. (a) Salvatierra, D.; Sánchez-Ruiz, X.; Garduño, R.; Cervelló, E.; Jaime, C.; Virgili, A.; Sánchez-Ferrando, F. Tetrahedron 2000, 56, 3035. (b) Beà, I.; Jaime, C.; Redondo, J.; Bonnet, P.; Torrens, A.; Frigola, J. Supramol. Chem. 2001, 14, 33. (c) Entrena, A.; Jaime, C. J. Org. Chem. 1997, 62, 5923.

4. (a) Bonnet, P.; Jaime, C.; Morin-Allory, L. J. Org. Chem. 2001, 66, 689. (b) Bonnet, P.; Jaime, C.; Morin-Allory, L. J. Org. Chem. 2002, 67, 8602. (c) Bonnet, P.; Beà, I.; Jaime, C.; Morin-Allory, L. Supramol. Chem. 2002, 14, 33. (d) Lino, A. C. S.; Takahata, Y.; Jaime, C. J. Molec. Struct. (THEOCHEM) 2002, 594, 207. (e) Beà, I.; Jaime, C.; Kollman, P. A. Theor. Chem. Acc. 2002, 108, 286. (f) Beà, I.; Cervelló, E.; Kollman, P. A.; Jaime, C. Comb. Chem. and High Throughput Screening 2001, 4, 605.

5. (a) Beà, I.; Ph.D. Dissertation. UAB. 2001. (b) Maestre, I; Ph.D. Dissertation, UAB. 2004.

6. Ivanov, P. M.; Jaime, C. J. Phys. Chem. B 2004, 108, 6261.

7. Brady, B.; Darcy, R.; O'Sullivan, J. J. Incl. Phenom. 1999, 33, 39.

8. (a) Liu, Y.; Li, L.; Chen, Y. J. Incl. Phenom. 2002, 42, 151. (b) Liu, Y.; Li, L.; Zhang, H. Y, Zhao, Y. -L.; Wu, X. Macromolecules 2002, 35, 9934.

9. Chiu, S. H.; Myles, D. C.; Garrel, R. L.; Stoddart, J. F. J. Org. Chem. 2000, 65, 2792.

10. Liu, Y.; Li, L.; Zhang, H. Y.; Song, Y. J. Org. Chem. 2003, 68, 527.

11. Nelissen, H. F. M.; Feiters, M. C.; Nolte, R. J. M. J. Org. Chem. 2002, 67, 5901.

12. Yamamura, H.; Yamada, S.; Kohno, K.; Okuda, N.; Araki, S.; Kobayashi, K.; Katakai, R.; Kano, K.; Kawai, M. J. Chem. Soc., Perkin Trans. 1 1999, 2943.

13. For examples see: Engeldinger, E.; Armspach, D.; Matt, D. Chem. Rev. 2003, 103, 4147.

14. Lecourt, T.; Mallet, J. M.; Sinay, P. Tetrahedron Let. 2002, 43, 5533.

15. Steed, J. W.; Atwood, J. L. Supramolecular Chemistry; John Wiley \& Sons, Ltd., 2000; p 363.

16. Levine, I. N. Química Cuántica. AC Textos Científicos. $1^{\text {st }}$ Edn, 1977.

17. Bertrán, J.; Branchadell, V.; Moreno, M.; Sodupe, M. Química Cuántica. Síntesis. $1^{\text {st }}$ Edn 2000; Ch. 12 and 13.

18. Lipkowitz, K. B. Chem. Rev. 1998, 98, 1829.

19. Ivanov, P. M. Lecture Notes in Molecular Mechanics; UAB., $1^{\text {st }}$ Edn, 1996.

20. Allinger, N. L.; Yuh, I. H.; Lii, J. H. J. Am. Chem. Soc. 1989, 11, 8551.

21. Leach, A. R. Molecular Modelling; Principles and Applications; Prentice Hall. $2^{\text {nd }}$ Edn 2001; Ch. 4, 5, 7, 8, 9 and 11.

22. van Gunsteren, W. F.; Berendsen, H. J. C. Angew. Chem., Int. Ed. 1992, 29, 992.

23. Macromodel 5.0. X Cluster User Manual, Version 1.0. Department of Chemistry, Columbia University, NY, 1993.

24. Polac, E.; Ribiere, G. Revue Francaise Inf. Rech. Oper. 1969, 16-R1, 35.

25. Ryckaert. J. P. Mol. Phys. 1985, 55, 549.

26. Berendsen, H. J. C.; Postma, J. P. M.; Van Gunsteren, W. F.; DiNola, A.; Haak, J. R. J. Chem. Phys. 1984, 81, 3684. 